\title{
Application of material from used car tyres in geotechnics - an environmental impact analysis
}

\author{
Aleksander Duda ${ }^{\text {Corresp., } 1}$, Małgorzata Kida ${ }^{2}$, Sabina Ziembowicz ${ }^{2}$, Piotr Koszelnik ${ }^{2}$ \\ 1 Department of Roads and Bridges, Faculty of Civil and Environmental Engineering and Architecture, Rzeszow University of Technology, Rzeszow, Poland \\ 2 Department of Chemistry and Environmental Engineering, Faculty of Civil and Environmental Engineering and Architecture, Rzeszow University of \\ Technology, Rzeszow, Poland
}

Corresponding Author: Aleksander Duda

Email address: aduda@prz.edu.pl

This work begins with a literature-based discussion of the hazardous-waste problem represented by car tyres as hazardous waste, along with possible ways in which they might be utilised or managed. The impact of the material on the environment is characterised in the process, not least in the context of pollutants leached to the aquatic environment. Input in terms of new research results concerns the impact on water and soil of material from used car tyres being used in geotechnics. Specifically, tyre bales comprising 100-140 car vehicle tyres compressed into a lightweight block and secured by galvanised steel tie wires running around the length and depth of the bale, were researched, having been immersed in basins with alkaline and acidic water following initial preparation and pre-washing. The aim was to in some sense simulate - respectively conditions in which rain and surface / ground water are involved, or else acid rain. To do that, the tyre bales were placed in the water for 120 days, with emerging leachate analysed after set intervals of time, with a view to changes in key physicochemical parameters of water being noted, as well as signs of the leaching of both undesirable components and priority substances, from tyres into the aqueous medium. Washing of the tyre bales was shown to induce slight pollution of water, with limited exceedance of normative values in respect of OWO content. However, this increase was not due to leaching of the Persistent Organic Pollutants tested for, but may rather have reflected contamination of tyres used, e.g. of soil at the place of previous storage. In general, waste water arising does not therefore contain substances that would stand in the way (legally) of its being discharged into a combined sewer system. Similar conclusions were arrived at through analysis of the leaching of pollutants from tyre bales exposed in the aforementioned pools of water of neutral and acidic reaction. Wastewater arising was not enriched significantly in impurities (be these metals, PAHs, phthalates, selected anions or cations), and there were therefore no exceedances of standards imposed for wastewater 
discharged to either waters or soil. 
2 Application of material from used car tyres in 3 geotechnics: an environmental impact analysis

4

5

6

7

8

Aleksander Duda ${ }^{1}$, Małgorzata Kida ${ }^{2}$, Sabina Ziembowicz ${ }^{2}$, Piotr Koszelnik ${ }^{2}$

${ }^{1}$ Department of Roads and Bridges, Faculty of Civil and Environmental Engineering and Architecture, Rzeszów University of Technology, Rzeszów, Poland

${ }^{2}$ Department of Chemistry and Environmental Engineering, Faculty of Civil and Environmental Engineering and Architecture, Rzeszów University of Technology, Rzeszów, Poland

Corresponding Author: Aleksander Duda ${ }^{1}$

al. Powstańców Warszawy 12, Rzeszów, 35-959, Poland

Email address: aduda@prz.edu.pl

\section{Abstract}

This work begins with a literature-based discussion of the hazardous-waste problem represented by car tyres as hazardous waste, along with possible ways in which they might be utilised or managed. The impact of the material on the environment is characterised in the process, not least in the context of pollutants leached to the aquatic environment. Input in terms of new research results concerns the impact on water and soil of material from used car tyres being used in geotechnics. Specifically, tyre bales comprising 100-140 car vehicle tyres compressed into a lightweight block and secured by galvanised steel tie wires running around the length and depth of the bale, were researched, having been immersed in basins with alkaline and acidic water following initial preparation and pre-washing. The aim was to in some sense simulate respectively - conditions in which rain and surface / ground water are involved, or else acid rain. To do that, the tyre bales were placed in the water for 120 days, with emerging leachate analysed after set intervals of time, with a view to changes in key physicochemical parameters of water being noted, as well as signs of the leaching of both undesirable components and priority substances, from tyres into the aqueous medium. Washing of the tyre bales was shown to induce slight pollution of water, with limited exceedance of normative values in respect of OWO content. However, this increase was not due to leaching of the Persistent Organic Pollutants tested for, but may rather have reflected contamination of tyres used, e.g. of soil at the place of previous storage. In general, waste water arising does not therefore contain substances that would stand in the way (legally) of its being discharged into a combined sewer system. Similar conclusions were arrived at through analysis of the leaching of pollutants from tyre bales exposed in the aforementioned pools of water of neutral and acidic reaction. Wastewater arising was not enriched significantly in impurities (be these metals, PAHs, phthalates, selected anions 
40 or cations), and there were therefore no exceedances of standards imposed for wastewater

41 discharged to either waters or soil.

\section{Introduction}

43 Globally, the rubber and car industries generates hundreds of millions of used tyres each year.

44

45

46

47

48

49

50

51

52

53

54

55

56

57

58

59

60

61

62

63

64

65

66

67

68

69

70

71

72

73

74

75

76

77

78
That mass is foreseen to increase steadily, at a rate in line with the increase in the number of motor vehicles. In the EU as a whole, 2017 saw around 3.4 million tons of used tyres of passenger cars generated, while figures for Poland include 275,000 tonnes (along with 200,000 tonnes of truck tyres) (Central Statistical Office, 2017). Similar data on the production of passenger car tyres in Poland are available from the European tyre and Rubber Manufacturers Association - ETRMA. The conclusion (ETRMA, 2017) would thus be that $79 \%$ of the tyres produced in Poland are recycled or recovered, with $42 \%$ becoming recycled material (granulation tyres) or retread, along with 29\% going for energy recovery (burning in cement kilns) or energy recycling (pyrolysis). The fact that the remaining $21 \%$ of spent tyres go unused must represent great potential for the tyres to gain use in other parts of the economy, e.g. in civil engineering. Rubber material from tyre-recycling (in fine or granulated form) does gain successful use in road construction, where the application is to modify the composition of asphalt (Liu et al., 2018). The bituminous surfaces arising from this activity are demonstrably more durable and more flexible, of lesser luminance, and of greater resistance to abrasion. They also achieve greater roughness, while serving to reduce the level of noise arising as tyres still in use on vehicles make contact.

In addition, rubber also gains use in the manufacture of clothing, car mats, mats for farm animals, wipers, playground surfaces, and so on (Duda et al., 2016). However, at present there are no examples in Poland of such pro-ecological solutions as direct tyre-recycling processes, whereby waste material processed to only a limited extent generates products of new and desired features. In countries such as the USA, France, Japan, the UK and Spain, as well as the Scandinavian countries, rubber aggregate in the form of shreds and chips is most often used as filler in earth and engineering constructions (embankments, retaining structures, backfill of abutments or drainage infrastructure). Similar applications appear where the combined form of the tyre bale is made use of. The first key advantage of such limited either fragmentation or compression of tyres is the way in which the recycling process then only takes between one-tenth or one-sixteenth as much energy as does the fragmentation of granular tyres, or tyre pyrolysis (Winter, Watts \& Johnson, 2006).

The high level of energy consumption inherent in far-reaching recycling of used tyres reflects the complex construction, wherein rubber is augmented by both textile and steel cord. This leaves used car tyres as extremely durable waste not naturally inclined to decompose and resistant to the action of water, various chemicals and extreme temperatures alike. This in turn means a major long-term threat associated with the possibility of fire taking hold at dumps where large numbers of tyres are present, as a result of vandalism (arson), the self-ignition of loose tyres or the role of nature (as with a lightning strike). Table 1 reports on selected cases of fire 
79

80

81

82

83

84

85

86

87

88

89

90

91

92

93

94

95

96

97

98

99

100

101

102

103

104

105

106

107

108

109

110

111

112

113

114

115

116

117

118

involving tyres that were being stored, in which the level of environmental hazard is very high indeed. For tyre fires release harmful chemicals capable of polluting air, water and soil.

Currently-applied methods of disposal of tyres do not suffice to guarantee environmental safety, hence the prohibition on the disposal of tyres at conventional landfills. In Poland, provisions of the Act of 11 May 2001 (Journal of Laws, 2001) in force in this regard require that tyre manufacturers recover $75 \%$ of the tonnage of manufactured tyres coming off the market, with at least $15 \%$ of that taking the form of recycling. As of now, the management of used car tyres in Poland entails material recycling (high energy granulation) and energy recovery (burning tyres in cement kilns). It will be clear from this that used tyres are among types of waste capable of exerting the most-severe environmental impact.

A background to that is the presence in tyres of dozens of different synthetic chemicals intended to confer the right properties, affect the flexibility, strength and durability of the product, and facilitate its processing. Table 2 shows the typical composition of the rubber from which tyres are made. The features determining the performance of a tyre, i.e. its resistance to mechanical damage and road conditions (e.g. as regards water and temperature), are also responsible for the difficulties associated with its redevelopment after use (PAS 107, 2012; Duda et al., 2016).

More specifically, a significant part of the environmental problem posed by rubber is down to additives, which include vulcanising agents, vulcanisation accelerators, vulcanisation accelerator activators, fillers that confer specific mechanical properties or reduce costs of production, softeners that facilitate processing and improve elasticity at low temperatures, antiaging substances and substances protecting against fatigue. Rainfall provides for the leaching of these substances out of tyres, which thus constitute a significant source of pollutants exerting a negative impact on the environment. According to Wagner et al. (Wagner et al., 2018) tires may contain additional substances in amount of 5 to 10 mass \%. Preservatives (halogenated cycloalkanes), antioxidants (amines, phenols), desiccants (calcium oxides), plasticizers (aromatic and aliphatic esters), processing aids (mineral oils, peptizers) can be leached from the matrix under favorable conditions.

Polycyclic aromatic hydrocarbons (PAHs) are among the substances washed out of tyres both new and used. Literature data suggested that, in circumstances of a basic $\mathrm{pH}$, the concentrations of polycyclic aromatic hydrocarbons leached from rubber chips may exceed limit values set for drinking water. PAHs can derive from soot, special fillers or residual oil. New car tyres differ from used ones in generating slightly higher concentrations of eluted PAHs (1.2 ppb in new tyres and 0.6 ppb in old ones) (Miller \& Chadik, 1993; Threshold odor number calculations, available at: http://www.opcertschool.com/, accessed 02 February 2020; National Secondary Drinking Water Regulations, available at: https://www.epa.gov/, accessed 02 February 2020). In addition, research by Capolupo et al. (Capolupo et al., 2020) conducted on the elution of various components from car tires in the form of microplastics (grain diameter $<1$ $\mathrm{mm}$ ) into freshwater and marine leachates confirm the presence of such substances as benzothiazole, $2(3 \mathrm{H})$-benzothiazolone and phthalimide. Benzothiazole was found in the highest 
119

120

121

122

123

124

125

126

127

128

129

130

131

132

133

134

135

136

137

138

139

140

141

142

143

144

145

146

147

148

149

150

151

152

153

154

155

156

157

concentrations in the freshwater and marine leachates $(2,313$ and $1,460 \mu \mathrm{g} / \mathrm{L}$, respectively). In turn, Hennebert et al. (Hennebert et al., 2014) confirms in its research the possibility of leaching phthalic acid esters (PAE) and polycyclic aromatic hydrocarbons from car tires.

Another group of substances potentially leaching from tyres includes organic compounds containing nitrogen and sulphur in their structure, serving as vulcanising agents, antioxidants and/or gases. Volatile organic compounds are used at the stages during which tyres are manufactured, in order to ensure adequate flexibility and viscosity. However, most VOCs are removed from the tyre as vulcanisation progresses, such that only about $8 \%$ of the original total ultimately remains in a tyre (Miller \& Chadik, 1993). According to Miller et al. (Miller \& Chadik, 1993) it is possible for there to be leaching from shreds of rubber chemical compounds, such as the aromatics (e.g. ketones) contained in gasoline, as well as carboxylic acids and aniline. According to Gasteiger (Gasteiger, 2010), during analysis of the leaching of components from car tires into water, aniline was the main identified leaching agent and occurred at levels almost an order of magnitude higher than other identified components. Leaching aniline from tires is also confirmed by Stier et al. (2020). Hennebert et al. (Hennebert et al., 2014) indicated that the concentration of aniline can reach $5.73 \mathrm{mg} / \mathrm{kg}$ in eluates from the shredded tires.

Leachates are also found to contain several other volatile substances, including benzene and methylbenzene. However, no benzene was found in the field leaching test, though the presence of methylbenzene at low concentrations was confirmed. In addition, trimethylbenzene and ethyltoluene were found to be at considerable concentrations. As mentioned above, these processes occur as tyres are in operation on vehicle wheels. However, the appearance of these pollutants in rainwater does not result in high concentrations, on account of the dilution effect.

Literature data (Grefe, 1989; Edil \& Bosscher, 1992; Miller \& Chadik, 1993; Humphrey \& Katz, 1995; Kim, 1995, Selbes, 2009, Turner \& Rice, 2010; Hennebert et al. 2014; Selbes et al., 2015; Redondo-Hasselerharm et al., 2018; Liu et al., 2020; Mohajerani et al. 2020) also confirm the presence of elements such as selenium, arsenic, calcium, iron, zinc and chromium in tyres; while silver and mercury were not found. Grefe (Grefe, 1989) reports that zinc, barium, iron and manganese were present in laboratory-modelled processes of leaching. Chromium has also been detected at low concentrations, while those of iron and manganese have both been found to exceed permissible values for drinking water (Threshold odor number calculations, available at: http://www.opcertschool.com/, accessed 02 February 2020; National Secondary Drinking Water Regulations, available at: https:/www.epa.gov/, accessed 02 February 2020).

Kim (Kim, 1995) presents the results of leaching from rubber chips, with samples taken and tested (filtered or unfiltered) 790 and 830 days on from the onset of the washing process in columns consisting of a mixture of rubber chips and soil or else soil itself. Analyses were performed for such metals as zinc, barium, arsenic, lead and chromium, but concentrations in samples tested were not seen to exceed levels permissible for drinking water. The highest concentration of lead was recorded with unfiltered leaching carried out on a column consisting of a mixture of rubber chips and soil.

PeerJ reviewing PDF | (2020:02:45682:1:1:NEW 12 Jun 2020) 
158

159

160

161

162

163

164

165

166

167

168

169

170

171

172

173

174

175

176

177

178

179

180

181

182

183

184

185

186

187

188

189

190

191

192

193

194

195

196

197

Miller et al. (Miller \& Chadik, 1993) also analysed the effect of $\mathrm{pH}$ on the quality and level of leaching of chemical compounds from tyres, finding no correlation between $\mathrm{pH}$ value and concentrations of leached metal ions. According to the authors, this may reflect the adsorption of metal ions by rubber chips. Other studies (Liu, Mead \& Stacer,1998; Mohajerani et al., 2020) have shown that metals are leached from rubber materials at the highest concentrations where prevailing conditions are acidic. On the other hand, PAHs and petroleum hydrocarbons are leached from rubber materials in highest concentrations where $\mathrm{pH}$ conditions are basic. The Environment Agency Regulatory Position Statement 085 indicates that tire bales should not be used below the water level in Source 1 or 2 Conservation Zones or in very acidic environments (peat bogs etc.) where the soil $\mathrm{pH}$ is 5 or less, in order to reduce risk of leaching. However, the latest scientific reports include Mohajerani et al. (2020) still indicate the need for further comprehensive research on the leaching of toxic heavy metals and other substances from used rubber products. Indicates the need to test leachate at various $\mathrm{pH}$ values and the ratio of liquids to solids.

At present tyre bales are being successfully used in mainly civil engineering applications, in landfill construction where innovation is less constrained than in other sectors of the construction industry, and in unpaved roads (Winter, Watts \& Johnson, 2006, Simm, Winter \& Waite, 2008). It is rubber material from tyres recycled in the form of bales that is best suited to civil-engineering applications, especially in transport infrastructure, geotechnics and hydrotechnics.

The Faculty of Civil and Environmental Engineering and Architecture of Rzeszow University of Technology has been joined by executive and design companies within the framework of the ReUse research project aimed at developing and implementing an innovative, cheap and environmentally-friendly building material recycled from waste in the form of tyre bales. Engineering constructions filled with tyre bales are exposed to aggressive rainwater, potentially causing leaching of organic and/or inorganic compounds from the tyres generally considered hazardous to the environment and people.

Intact tyres are less prone to leaching than shredded tyre rubber. The leaching research indicates that the available leaching surface on the tyre material is an important leaching factor, especially for zinc and PAH. Decreasing the available surface by using larger fractions of tyre shreds is favourable in an environmental point of view [Edeskär, 2006; Selbes et al., 2015]. Large size tire shreds can be also an economical alternative compared to the small size tire shreds in the construction of the tire shred embankment [Khan \& Shalaby, 2002]. In addidion, Birkholz et al. showed that fresh shredded tyre produced a moderate toxic threat to aquatic species, if run-off was not diluted. However, the danger receded as the material aged. However, according to Gualtieri et al. (Gualtieri et al., 2005) the growth of tire particles used in the sample does not correlate directly with $\mathrm{Zn}$ leaching, because particle aggregation may occur, thus limiting the surface area of exposed granular material. Laboratory tests of heavy metal leaching from new and used tires were also conducted by Fenner and Clarke (Fenner \& Clarke, 2003). Used tires have been exposed to the aquatic environment for thirteen years. The results show that 
198

199

200

201

202

203

204

205

206

207

208

209

210

211

212

213

214

215

216

217

218

219

220

221

222

223

224

225

226

227

228

229

230

231

232

233

234

235

236

237

the factor limiting their use may be the release of cadmium and leaching of vulcanizing chemicals. It has been found that tires can be used sustainably in a river or coastal environment, provided that local conditions at the construction site are carefully considered. The purpose of the research carried out and described in this article has been to determine whether tyre bales cause pollution of rainwater, and then groundwater and soil; as well as what level of leaching of undesirable substances takes place.

\section{Materials \& Methods}

\section{Tyre bales}

The pressing and packing of tyres has represented a response to the obligation that the input of tyre-related components be reduced, also given the increasing risk that the tyres present at dumps might self-ignite. Tyre bales considerable potential for use in construction, particularly where their low density and ease of handling give them an advantage. Tyre bales used in the experiment comprised 135 whole waste passenger-vehicle tyres compressed into a lightweight block with the weight of around $1,000 \mathrm{~kg}$ and the density of circa $500 \mathrm{~kg} / \mathrm{m} 3$. Each bale contained only one type and size of tyres. The bales were produced according to PAS 108 (PAS $108,2007)$ in a tyre baler capable of compressing whole tyres to reach the density not lower than $420 \mathrm{~kg} / \mathrm{m} 3$. The bales measured approximately $1.30 \times 2.05 \times 0.75 \mathrm{~m}$ and were secured by six galvanized steel tie wires running around the length and depth of the bale (Fig. 1). Apart from tyre bale dimensions -slightly modified to facilitate transport - the remaining PAS 108 (PAS 108, 2007) production requirements, i.e. compressing force, density (mass/volume ratio) and number and tension of steel tie wires, were fulfilled.

\section{The impact of tyre bales on water quality}

The environmental testing of tyre bales proceeded in stages. Stage I saw the tyres from tyre bales washed with tap water (WW) (Fig. 2), with both the collected leachate (M) and inputting water made the subject of physico-chemical analyses. The used tyres involved were obtained from a tyre store and not cleaned preliminarily in any way. In Stage II of the testing, washed tyre bales were placed in two separate pools (Fig. 3), i.e. one filled with tap water at $\mathrm{pH} 8.71$ and a second acidified to $\mathrm{pH} 3.87$. The goal was for the first pool to mirror conditions in which rain and surface/ground water is present, while the second simulated situations of acid rain.

The tyre bales were left immersed for 120 days, with sampling on days $0,21,68,99$ and 120. Based on the reviewed literature and previous experience in site contamination, factors that may affect the rate of leaching and/or the concentration of tyre leachate compounds in soil, surface water and groundwater also include contact time with water. The longer the tyres are in contact with water, the greater the risk of groundwater contamination. In our research, the experiment lasted up to 120 days due to the durability of the tires. Also, the half-life times of plastics can reach several dozen days, for example in marine water - 60 days, in soil -120 days, in fresh or estuarine water - 40 days, in marine sediment - 180 days, in fresh or estuarine sediment - 120 days [EC 2007; Muniyasamy et al., 2019]. The purpose of this experiment was to make sure that the effect of prolonged contact of tires with water would not be leaching harmful 
238

239

240

241

242

243

244

245

246

247

248

249

250

251

252

253

254

255

256

257

258

259

260

261

262

263

264

265

266

267

268

269

270

271

272

273

274

275

276

277

components from the tires. Due to the fact that no significant changes in water composition were observed after 120 days, it was decided not to continue the experiment any longer. All the experiments were done in duplicated, with an observed deviation of less than $5 \%$. Additional effluent, formed in the sludge-well located at the bottom of the test setup (Fig. 4) - as intended for mechanical tests of backfill pressure distribution - was also analysed (Duda \& Siwowski, 2020a, Duda \& Siwowski, 2020b). Samples there were taken after the first flushing of tyres, and on the last day of the trial.

The scope of the physico-chemical analyses of generated waters and wastewaters reflected known technological parameters of tyres, information in the literature, and indicators listed in the EU's Water Framework Directive. Results were in particular set against provisions in the Polish law implementing the Directive, as well as Directive 2010/75/EU of the European Parliament and of the Council of November 24, 2010 on industrial emissions (integrated pollution prevention and control), as recast.

Where the Polish domestic law was concerned, reference was made to "Regulation 1", i.e. the Regulation of the Minister of the Maritime Economy and Inland Navigation of 12 July 2019 on substances particularly harmful to the aquatic environment and conditions to be met when introducing sewage into waters or into the ground, as well as when discharging rainwater or snowmelt into waters or for water equipment (the Official Journal of Laws of 2019, item 1311); as well as "Regulation 2", i.e. the Regulation of the Minister of the Maritime Economy and Inland Navigation of 29 August 2019 on the requirements to be met by surface waters used to supply the population with water intended for human consumption (the Official Journal of Laws of 2019, item 1747)

The comparison of the results obtained with the standards arising from "Regulation 1" is of decisive importance where any further treatment of effluent arising is concerned, while the comparison with standards laid down in "Regulation 2" represents auxiliary information in this regard. The scope and characteristics of methodologies involved in the physico-chemical analysis are as summarised in Table 3.

\section{Results}

\section{Stage I. Tyre-washing}

The test results presented in Table 4 confirm a documentable change in the composition of the washing medium, whose $\mathrm{pH}$ after flushing increased from 8.98 to slightly above 9 . This value slightly exceeds the permissible recommended limit value for surface water used to supply the population with drinking water and for sewage discharged into waters or into the ground.

However, as the water used in washing was already alkaline, given the $\mathrm{pH}$ of 8.98 , the actual enrichment in alkalizing substances that was involved was limited.

Increases in electrolytic conductivity, suspension and solutes were also observed, denoting that the initial washing of tyres sees solids and dissolved substances transferred from surfaces into the water. Due to the marked attendant increase in total organic carbon (TOC) from 0.0985 to $40.90 \mathrm{mgC} \mathrm{L}^{-1}(\mathrm{M})$, this leachate does not meet the standards set out in the Regulations 
278

279

280

281

282

283

284

285

286

287

288

289

290

291

292

293

294

295

296

297

298

299

300

301

302

303

304

305

306

307

308

309

310

311

312

313

314

315

316

317

cited above. However, the tyre bales were in a dirty state, making it inevitable that large amounts of dirt will be removed by initial washing.

At a more detailed level, wastewater generated was found to have an increased concentration of total nitrogen that exceeded the $5 \mathrm{mg} \mathrm{L}^{-1}$ permissible content for treated waters meeting the needs of the population as stipulated in "Regulation 2". The content of phosphates in leachate also fails to meet requirements for water serving as a source of water supply. Once again, however, it needs stressing that the determined concentrations were far below those permitted in the case of wastewater.

Furthermore, tyre leachate was not found to contain either PAHs and phthalates used as plasticisers or heavy metals (notably copper and cadmium). Tested concentrations of organics were below the detection levels possible with the method deployed. Meanwhile, lead and zinc were detected, but at concentrations not exceeding threshold values. The presence of the latter metals reflects the composition of tyres, which are $1 \%$ by weight of zinc and about $0.005 \%$ of lead, on average.

According to Sebels et al. (Selbes et al., 2015) operation under neutral pH conditions, prewashing of tires, use of larger size tire chips, and removal of metal wires prior to application will reduce the impact of tire recycle and reuse.

\section{Stage II. Analysis of pollutant leaching from tyre bales}

Table 5 summarises results for leaching from tyre bales into tap water under slightly alkaline or acid conditions. Tires are the result of vulcanization, which is initiated by temperature. However, during use, this material absorbs an additional amount of energy, which causes that this material becomes harder over time and may crack. In addition to reducing the utility values, cracks release various tire components into the environment. Where the alkaline water was concerned, no exceedances of indicators were noted in relation to "Regulation 1". There was also no leaching of organic compounds, be these either PAHs or phthalates (as plasticisers). In the research of Gomes et al. (Gomes et al., 2010) PAH leaching was also negligible. This confirms the fact that the new tires show higher concentrations of organic compounds including PAHs than the old tires (new tires $=1.2 \mathrm{ppb}$; old tires $0.6 \mathrm{ppb}$ ) (Engstrom et al. 1994). On day 21, the TOC concentration increased was elevated - at 16.82 (as opposed to an initial 1.62) $\mathrm{mgC} \mathrm{L}^{-1}$. The trend was maintained to $12.57 \mathrm{mg} \mathrm{L}^{-1}$ until day 120 and the trial's end. These values fall within categories A2 and A3 where water taken for treatment is concerned, meaning a level also present in most Polish rivers.

The concentration of phosphate increased immediately after tyre bales were inundated, though still remaining compliant with the standards set for wastewater in "Regulation 2". Equally, the phosphate concentration was actually very low on subsequent measuring days, perhaps indicating a one-off, perhaps incidental, phenomenon reflecting the situation of given individual tyres. No enrichment of water in contact with tyres by the analysed anions or cations was reported, and neither was there apparently significant leaching of the heavy metals tested for. Just after 21 days the presence of tested metals in water was observed, however in very low concentrations. Depaolini et al. (Depaolini et al., 2017) also studied the leaching of heavy metals 
318 from rubber. The values they measured were on average very low, often below the detection 319 limit.

320

321

322

323

324

325

326

327

328

329

330

331

332

333

334

335

336

337

338

339

340

341

342

343

344

345

346

347

348

349

350

351

352

353

354

355

356

357

The acid water tested for the various indicators also failed to note any "Regulation 1" exceedances. An alkalizing effect of the eluted substances was observed, with the result that the $\mathrm{pH}$ of the water rose steadily from 3.87 on day 0 to 6.25 on day 120 . This is a desirable phenomenon, suggesting that tyre bales coming in contact with acid rain will in some sense treat it. There was also no reported leaching of organics - either PAHs or phthalates. As with the slightly-alkaline waters, a day-21 elevation of TOC as compared with the initial situation was noted - to 18.37 (as compared with 3.82) $\mathrm{mgC} \mathrm{L}^{-1}$. This was still the case on day 120, though the value was back down to $10.66 \mathrm{mg} \mathrm{L}^{-1}$ by then. Selbes et al. (Selbes et al., 2015) when analyzing the leaching of dissolved organic carbon, dissolved nitrogen and selected inorganic components from used tires, found that the components associated with the rubber part of tires (DOC, DN, zinc, calcium, magnesium etc.) showed an initial fast and then slow release. On the other hand, a constant leaching rate of iron and manganese has been observed, which is attributed to metal wires inside the tires.

However, the obtained values once again fall within categories A2 and A3 where waters taken for treatment are concerned, which is again the level to be observed in most Polish rivers. No enrichment by anions (including phosphates) or cations was to be noted thanks to contact between tyres and water. Nor was leaching of heavy metals reported.

On analysis of the water collected from the sedimentation well, it was clear (Table 5) that first flooding of a tyre bale results in water being alkalized to $\mathrm{pH} 10.64$. However, the enrichment of water in more-specific components is limited, with no exceedances of limit values for wastewater involved. The samples taken on day 120 of the experiment were slightly more contaminated, given the deposition of impurities originating in the tyre bales. In particular, total suspension was higher at 9.0 (as opposed to 1.145) $\mathrm{mg} \mathrm{L}^{-1}$ ), while sulphate concentration was at $273 \mathrm{mg} \mathrm{L}^{-1}$ compared with an initial 0 , and water hardness ( $\mathrm{Mg}$ and $\mathrm{Ca}$ concentration) was also greater. In each case, however, the increases were to levels remaining below those allowable for wastewater in accordance with "Regulation 1". The organic compounds tested for were not found to be present, while concentrations of heavy metals remained were close to the minimum quantifiable limit. The reasons for the decrease or increase of the given parameters are the physicochemical changes that occur during the prolongation of the contact of tires with water. The concentrations of some substances increase as the contact time of the tires with water increases. Some of the substance, e.g. dibutyl phthalate, is leached from the tires and then transformed into other substances or completely degraded. others, in turn, are transformed into insoluble ones, which are, for example, sorbed on the walls of tires or solid particles in water. Sometimes the differences in the amount of a given substance result from the accuracy of the devices used for the determination, especially for low-concentration compounds. Selbes et al. (Selbes et al., 2015) conducted research on leaching of dissolved organic carbon, dissolved nitrogen and selected inorganic components from used tires. Different tire particle sizes were exposed to leaching solutions with a $\mathrm{pH}$ in the range 3.0 to 10.0 for 28 days. DOC and DN

Peer) reviewing PDF | (2020:02:45682:1:1:NEW 12 Jun 2020) 
358

359

360

361

362

363

364

365

366

367

368

369

370

371

372

373

374

375

376

377

378

379

380

381

382

383

384

385

386

387

388

389

390

391

392

393

394

395

396

leaching was found to be greater for smaller tire chippings. However, the leaching of inorganic components was independent of size. In general, basic $\mathrm{pH}$ conditions increased the leaching of DOC and DN, while acidic $\mathrm{pH}$ conditions led to increased metal concentrations. Elution was minimal around neutral $\mathrm{pH}$ values for all monitored parameters. Although the total amounts of leaching substances were different, the observed leaching rates were similar for all tire chip sizes and leaching solutions.

\section{Discussion}

In this study, heavily worn tires that could already be free of mobile forms of pollution were used. The results obtained indicate the environmental safety of their use. No evidence has been obtained that the use of compressed tyre bales increases the concentration of substances in the tires. It has not been found that this material increases the occurrence of metals, chlorides and sulfates, which have an impact on secondary (aesthetic) drinking water standards. Particularly important is the lack of exceedances for zinc, which is used in the production of tires in large quantities (Rhodes et al. 2012). This confirms the findings of other researchers who do not obstruct leaching of this metal from waste tyre bales (Simm et al. 2004). Hyland and Shulman (2003) summarise the results of laboratory and field studies to determine the level of leachates from tyres. The result indicates that for all regulated metals and organics the results for postconsumer tyres are well below regulatory levels. Substances which could potentially leach from post-consumer tyre materials are already present in groundwater in developed area. Studies suggest that leachate levels for the majority of contaminants fall below the allowable regulatory limits and will have negligible impact on the general quality of water in close proximity to tyres. However, the National Water Research Institute in Canada conducted tests to determine the toxicity of new car tires and their impact on aquatic animals. Research reports published by the Institute show that both old and new tires are toxic to the analyzed rainbow trout. According to the authors of the study, the toxicity of tires is not related to the substances collected during their use or storage, but is only the result of production processes. A higher level of toxicity has been reported for used car tires than for unused new tires (Day et al. 1993). However, research conducted by Redondo-Hasselerharm et al. (Redondo-Hasselerharm et al., 2018) indicate that the car tire, including the chemicals associated with this material, did not adversely affect the four freshwater benthic invertebrates. According to the authors, the car tire is a low risk for freshwater benthic invertebrates. However, the potential long-term effects caused by the slow release and gradual environmental increase of bioavailable zinc and other substances caused by aging of the rubber particles are not expressed in these experiments and still require further research.

\section{Conclusions}

1. The washing of tyre bales and collection and disposal of effluent generated will suffice to protect the natural environment where the resulting product is embedded against contamination. 
397

398

399

400

401

402

403

404

405

406

407

408

409

410

411

412

413

414

415

416

417

418

419

420

421

422

423

424

425

426

427

428

429

430

431

432

433

434

435

2. The effluent from tyre-washing is enriched only slightly at the time of contact, to the extent that visual checks on tyres used to form a bale (with non-selection of the most-soiled tyres) may render washing prior to installation unnecessary.

3. There is no evidence that tyre bales embedded in the ground represent a real or potential source of pollution, or pose a threat that water and soil quality in the vicinity will deteriorate.

4. The quality of sedimentation-well sludge is also satisfactory, to the extent that no treatment as per the regulations for industrial effluent are necessitated.

5. The conditions of the simulation may reasonably be deemed extreme, given immersion and thus constant contact between tyres and water for a period of 120 days. In real conditions, tyre bales will be in contact with water for a few hours, after which various changes associated with self-cleaning, concentration and a density gradient will ensue, to the extent any negative impact on the environment is further curbed.

\section{Acknowledgements}

The authors thank D. Sobala that directing a research program and technical staff builds and supports full scale trial.

\section{References}

Act of 11 May 2001 on the obligations of producers of certain products and on the product and deposit fee (Journal of Laws No. 63, item 639, as amended). Available at http://prawo.sejm.gov.pl/isap.nsf/download.xsp/WDU20010630639/U/D20010639Lj.pdf (accessed 02 February 2020)

Birkholz DA, Belton KL, Guidotti TL. 2003. Toxicological evaluation for the hazard assessment of tire crumb for use in public playgrounds. Journal of the Air \& Waste Management Association, 53(7), 903-907.Central Statistical Office. Production of industrial products in 2017. Available at https://stat.gov.pl/obszary-tematyczne/przemysl-budownictwo-srodkitrwale/przemysl/produkcja-wyrobow-przemyslowych-w-2017-roku,3,15.html (accessed 02 February 2020)

Chemical Hazards and Poisons Report From the Chemical Hazards and Poisons Division, 2003. Available at https://assets.publishing.service.gov.uk/government/uploads/system/uploads/attachment_data/ file/202884/rep_Chapr1Dec2003.pdf (accessed 02 February 2020)

Capolupo M, Sørensen L, Jayasena KDR, Booth AM, Fabbri E. 2020. Chemical composition and ecotoxicity of plastic and car tire rubber leachates to aquatic organisms. Water research, 169, 115270.

Day KE, Holtze KE, Metcalfe-Smith JL, Bishop CT, Dutka BJ. 1993. Toxicity of leachate from automobile tires to aquatic biota. Chemosphere, 27(4), 665-675.

Depaolini, A. R., Bianchi, G., Fornai, D., Cardelli, A., Badalassi, M., Cardelli, C., \& Davoli, E. (2017). Physical and chemical characterization of representative samples of recycled rubber from end-of-life tires. Chemosphere, 184, 1320-1326. 
436

437

438

439

440

441

442

443

444

445

446

447

448

449

450

451

452

453

454

455

456

457

458

459

460

461

462

463

464

465

466

467

468

469

470

471

472

473

474

475

Duda A, Sobala D, Siwowski T, Kaleta D. 2016. Wykorzystanie materiału z recyklingu opon samochodowych w budownictwie komunikacyjnym. Archiwum Instytutu Inżynierii Lądowej 21: 97-111.

Duda A, Siwowski T. 2020a. Experimental Investigation and First Application of Lightweight Abutment Backfill Made of Used Tyre Bales. In: Blikharskyy Z., Koszelnik P., Mesaros P. (eds) Proceedings of CEE 2019. CEE 2019. Lecture Notes in Civil Engineering, vol. 47. Springer, Cham, https://doi.org/10.1007/978-3-030-27011-7_9.

Duda A, Siwowski T. 2020b. Pressure evaluation of bridge abutment backfill made of waste tyre bales and shreds: Experimental and numerical study. Transportation Geotechnics, Volume 24, 2020, 100366, https://doi.org/10.1016/j.trgeo.2020.100366

EC, REACH Annex XIII. 2007. Criteria for the identification of persistent, bioaccumulative and toxic substances, and very persistent and very bioaccumulative substances.

Edeskär T. 2006. Use of tyre shreds in civil engineering applications: technical and environmental properties (Doctoral dissertation, Luleå tekniska universitet).

Edil TB, Bosscher PJ. 1992. Development of Engineering Criteria For Shredded Waste Tires in Highway Applications. Final Report Research.

Engstrom G, Lamb R. 1994. Using Shredded Waste Tires As a Lightweight Fill Material For Road Subgrades - A Summary Report, Minnesota Department of Transportation, Physical Research \& Geotechnical Engineering Sections, Material Research \& Engineering.

Environment Agency: Regulatory Position Statement 085, Use of PAS 108 tyre bales in civil engineering and landfill infrastructure works.

ETRMA - European Tyre \& Rubber Manufacturers Association. End of Life Tyres Management - Europe - 2017. Available at https://www.etrma.org/wp-content/uploads/2019/11/ELTManagement-Figures-2017-vf.xlsx.pdf (accessed 02 February 2020).

Gasteiger H. 2010. Polymer Electrolyte Fuel Cells 10, The Electrochemical Society.

Gomes J, Mota H, Bordado J, Cadete M, Sarmento G, Ribeiro A, ... \& Veloso I. 2010. Toxicological assessment of coated versus uncoated rubber granulates obtained from used tires for use in sport facilities. Journal of the Air \& Waste Management Association, 60(6), 741-746.

Grefe R. 1989. Review of Waste Characterization of Shredded Tires. Interdepartmental Memorandum, Wisconsin Department of Natural Resources, Madison, Wisconsin.

Gualtieri M, Andrioletti M, Vismara C, Milani M, Camatini M. 2005. Toxicity of tire debris leachates. Environment international, 31(5), 723-730.

Hennebert P, Lambert S, Fouillen F, Charrasse B. 2014. Assessing the environmental impact of shredded tires as embankment fill material. Canadian Geotechnical Journal, 51(5), 469-478. Humphrey DN, Katz LE. 1995. Water Quality Testing for Dingley Road Tire Chip Test Project. Report to Town Manager.

Hylands KN, Shulman V. 2003. Civil engineering applications of tyres. Viridis Report VR5. Crowthorne: TRL Limited.

Kim JY. 1995. Soil and Tire Chip Column Testing. Internal Report UW-Madison. 
476 Khan RA, Shalaby A. 2002. Performance of a road base constructed with shredded rubber tires.
477 In Proceedings of the Annual Conference of the Canadian Society for CIVIL Engineering,

477

478

479

480

481

482

483

484

485

486

487

488

489

490

491

492

493

494

495

496

497

498

499

500

501

502

503

504

505

506

507

508

509

510

511

512

513

514

515 Montreal, Que., Canada, June (pp. 5-8).

Liu HS, Mead JL, Stacer RG. 1998. Environmental Impacts of Recycled Rubber in Light Fill Applications. Summary \& Evaluation of Existing Literature. University of Massachusetts Lowell.

Liu L, Cai G, Liu S. 2018. Compression properties and micro-mechanisms of rubber-sand particle mixtures considering grain breakage. Construction and Building Materials, 187, 10611072.

Liu L, Cai G, Zhang J, Liu X, Liu K. 2020. Evaluation of engineering properties and environmental effect of recycled waste tire-sand/soil in geotechnical engineering: A compressive review. Renewable and Sustainable Energy Reviews, 126, 109831.

Miller WL, Chadik PA. 1993. A Study of Waste Tire Leachability in Potential Disposal and Usage Environments. Amended Final Report to Florida Department of Environmental Regulation No. SW67.

Mohajerani A, Burnett L, Smith JV, Markovski S, Rodwell G, Rahman MT, ... \& Maghool F. 2020. Recycling waste rubber tyres in construction materials and associated environmental considerations: A review. Resources, Conservation and Recycling, 155, 104679.

Muniyasamy S, Muniyasamy S, Mohanrasu K, Mohanrasu K, Gada A, Gada A, ... \& Paul V. 2019. Biobased Biodegradable Polymers for Ecological Applications: A Move Towards Manufacturing Sustainable Biodegradable Plastic Products. Integrating Green Chemistry and Sustainable Engineering, 215-253.

National Secondary Drinking Water Regulations. Available at:

https://www.epa.gov/sdwa/drinking-water-regulations-and-contaminants, accessed 02 February 2020

PAS 107:2012. Specification for the manufacture and storage of size reduced tyre materials. British Standards Institution. Available at https://www.wrap.org.uk/sites/files/wrap/MiniPAS107\%20approved\%2025april07.pdf (accessed 02 February 2020)

PAS 108:2007. Specification for the production of tyre bales for use in construction. British Standards Institution. Available at https://www.wrap.org.uk/sites/files/wrap/PAS\%20108\%202007.pdf (accessed 02 February 2020)

Redondo-Hasselerharm PE, de Ruijter VN, Mintenig SM, Verschoor A, Koelmans AA. 2018. Ingestion and chronic effects of car tire tread particles on freshwater benthic macroinvertebrates. Environmental science \& technology, 52(23), 13986-13994.

Rhodes E P, Ren Z, Mays DC. 2012. Zinc leaching from tire crumb rubber. Environmental science \& technology, 46(23), 12856-12863.

Selbes M. 2009. Leaching of dissolved organic carbon and selected inorganic constituents from scrap tires.

Peer) reviewing PDF | (2020:02:45682:1:1:NEW 12 Jun 2020) 
516 Selbes M, Yilmaz O, Khan AA, Karanfil T. 2015. Leaching of DOC, DN, and inorganic

517 constituents from scrap tires. Chemosphere, 139, 617-623.

518 Simm JD, Wallis M, Collins K. 2004. Sustainable Re-use of Tyres in Port, Coastal and River

519 Engineering; Guidance for planning, implementation and maintenance, HR Wallingford,

$520 \quad$ Report SR 669.

521 Simm JD, Winter MG, Waite S. Design and specification of tyre bales in construction.

522 Proceedings of the Institution of Civil Engineers-Waste and Resource Management 2008V;

523 161(2): 67-76. https://doi.org/10.1680/warm.2008.161.2.67

524 Stier JC, Horgan BP, Bonos SA. 2020. Turfgrass: Biology, use, and management (Vol. 104).

525 John Wiley \& Sons.

526 Threshold odor number calculations. Available at:

$527 \mathrm{http} / /$ www.opcertschool.com/media//DIR_6501/ef44b18872f090cbffff823fffffe904.pdf,

528 accessed 02 February 2020;

529 Turner A, Rice L. 2010. Toxicity of tire wear particle leachate to the marine macroalga, Ulva 530 lactuca. Environmental Pollution, 158(12), 3650-3654.

531 Winter MG, Watts GRA, Johnson PE. Tyre bales in construction. Crowthorne: TRL Limited; $532 \quad$ Report PPR 080; 2006. 


\section{Table $\mathbf{1}$ (on next page)}

Selected landfill tyre fires (Chemical Hazards and Poisons Report, 2003). 
1

\begin{tabular}{|c|c|c|c|}
\hline Location & Year & Duration & $\begin{array}{c}\text { Approx. } \\
\text { no. } \\
\text { of tyres }\end{array}$ \\
\hline Winchester, USA & 1983 & 9 month & $6-9$ million \\
\hline Powys, Wales & 1989 & 14 years & 10 million \\
\hline Hagersville, Canada & 1990 & 17 days & 8 million \\
\hline
\end{tabular}

2 


\section{Table 2 (on next page)}

Indicative composition of a tyre (PAS 107, 2012).

1) Lorry and OTR tyres contain higher proportions of natural rubber than passenger car tyres.

2) Silica replaces part of the carbon black in certain types of tyres.

3) Some of the additives include clays, which may be replaced in part in some tyres with recycled rubber crumb from waste tyres.

4) These approximate totals would be slightly higher if clays were replaced by recycled crumb rubber from waste tyres. 
1

\begin{tabular}{|c|c|c|c|}
\hline \multirow{2}{*}{ Ingredient } & Passenger car tyre & Lorry/truck tyre & $\begin{array}{c}\text { OTR (off-the-road) } \\
\text { tyre }\end{array}$ \\
\cline { 2 - 4 } & \multicolumn{3}{|c|}{$[\%]$} \\
\hline Rubber / Elastomers (1) & 47 & 45 & 47 \\
\hline Carbon black (2) & 21,5 & 22 & 22 \\
\hline Metal & 16,5 & 25 & 12 \\
\hline Textile & 5,5 & - & 10 \\
\hline Zinc oxide & 1 & 2 & 2 \\
\hline Sulphur & 1 & 1 & 1 \\
\hline Additives (3) & 7,5 & 5 & 6 \\
\hline Carbon-based materials (4) & 74 & 67 & 76 \\
\hline
\end{tabular}

2 


\section{Table 3 (on next page)}

The scope of research and research methodologies used

¿16PAH's - naphthalene (Na), acenaphthylene (Acy), acenaphthene (Ace), fluoren (Flu), phenanthrene (Fen), anthracene (An), fluoranthene (FI), pyrene (Pir), benzo [a] anthracene $(\mathrm{BaA})$, chrysene (Ch), benzo [b] fluoranthene (BbF), benzo [k] fluoranthene (BkF), benzo [a] pyrene (BaP), indeno [1,2,3-cd] pyrene (IP), dibenzo [ah] anthracene (DBA), benzo [ghi] perylene (BghiP). 


\begin{tabular}{|c|c|c|c|}
\hline Parameter & Unit & Method & Method details \\
\hline Reaction & $\mathrm{pH}$ & In situ meter & pH-meter, MultiLine P4 \\
\hline Temperature & ${ }^{\circ} \mathrm{C}$ & In situ meter & $\begin{array}{l}\text { HQ30D Digital single } \\
\text { channel multimeter }\end{array}$ \\
\hline Dissolved Oxygen & $\mathrm{mg} \mathrm{L}-1$ & In situ meter & $\begin{array}{l}\text { HQ30D Digital single } \\
\text { channel multimeter }\end{array}$ \\
\hline Conductivity in $20^{\circ} \mathrm{C}$ & $\mu \mathrm{S} \mathrm{cm}{ }^{-1}$ & In situ meter & $\begin{array}{c}\text { Conductivity meter, } \\
\text { Elmetron IP } 67\end{array}$ \\
\hline Total suspension & $\mathrm{mg} \mathrm{L}^{-1}$ & PN-EN-872:2007 & Samples volume: $100 \mathrm{~mL}$ \\
\hline Solutes & $\mathrm{mg} \mathrm{L}^{-1}$ & PN-78/C-04541 & Samples volume: $100 \mathrm{~mL}$ \\
\hline Total Organic Carbon & $\mathrm{mg} \mathrm{L}-1$ & PN-EN 1484:1999 & $\begin{array}{l}\text { Samples volume: } 20 \mathrm{~mL} \\
\text { TOC/N analyzer }\end{array}$ \\
\hline Total Nitrogen & $\mathrm{mg} \mathrm{L}^{-1}$ & PN-EN ISO 11905-1:2001 & $\begin{array}{l}\text { Samples volume: } 20 \mathrm{~mL} \\
\text { TOC/N analyzer }\end{array}$ \\
\hline $\begin{array}{c}\mathrm{NH}_{4}^{+}, \mathrm{NO}_{3}^{-}, \mathrm{Cl}^{-}, \mathrm{PO}_{4}^{3-}, \mathrm{SO}_{4}^{3-} \\
\quad \mathrm{Na}^{+}, \mathrm{K}^{+}, \mathrm{Mg}^{2+}, \mathrm{Ca}^{2+}\end{array}$ & $\mathrm{mg} \mathrm{L}^{-1}$ & PN-EN ISO 14911:2002 & $\begin{array}{l}\text { Samples volume: } 100 \mathrm{~mL} \\
\text { Ion chromatography } \\
\text { analysis }\end{array}$ \\
\hline Dibutyl phthalate, Bis(2-ethylhexyl) phtalate & $\mathrm{mg} \mathrm{L}^{-1}$ & PN-EN ISO 18856 & $\begin{array}{l}\text { Samples volume: } 100 \mathrm{~mL} \\
\text { SPE extraction } \\
\text { GC/MS chromatography } \\
\text { analysis } \\
\end{array}$ \\
\hline$\sum 16 \mathrm{PAH}$ 's & $\mathrm{mg} \mathrm{L}^{-1}$ & PN-ISO 18287 & $\begin{array}{l}\text { Samples volume: } 100 \mathrm{~mL} \\
\text { SPE extraction } \\
\text { GC/MS chromatography } \\
\text { analysis } \\
\end{array}$ \\
\hline $\mathrm{Cd}, \mathrm{Zn}, \mathrm{Pb}, \mathrm{Cu}$ & $\mathrm{mg} \mathrm{L}^{-1}$ & PN-EN ISO 11885 & $\begin{array}{l}\text { Samples volume: } 100 \mathrm{~mL} \\
\text { Mineralization in MARS } 6 \\
\text { microwave mineralizer } \\
\text { ICP-OES analysis }\end{array}$ \\
\hline
\end{tabular}




\section{Table 4 (on next page)}

Water quality and leachate after washing tyres.

WW - "zero" tap water, M - leachate from washing tyres from the existing tyre bale (130 pcs.)

+ Worn out individual tyres (130 pcs.), <LOQ - below the limit of quantification. 


\begin{tabular}{|c|c|c|c|c|c|c|c|}
\hline \multirow{2}{*}{ Parameter } & \multirow{2}{*}{ Unit } & \multicolumn{2}{|c|}{ Results } & \multirow{2}{*}{ Reg. 1} & \multicolumn{3}{|c|}{ Regulation 2} \\
\hline & & WW & $\mathbf{M}$ & & A1 & A2 & A3 \\
\hline Reaction & $\mathrm{pH}$ & 8.98 & 9.16 & $6.5-9$ & $\begin{array}{c}6.5- \\
8.5\end{array}$ & $5.5-9$ & $5.5-9$ \\
\hline Temperature & ${ }^{\circ} \mathrm{C}$ & 20.80 & 25.20 & 35 & 25 & 25 & 25 \\
\hline Dissolved Oxygen & $\%$ of sat. & 7.41 & 7.53 & - & $>70$ & $>50$ & $>30$ \\
\hline Conductivity in $20^{\circ} \mathrm{C}$ & $\mu \mathrm{S} \mathrm{cm}^{-1}$ & 454.00 & 503.00 & - & 1000 & 1000 & 1000 \\
\hline Total suspension & $\mathrm{mg} \mathrm{L}^{-1}$ & 30 & 115 & 35 & 25 & 30 & 35 \\
\hline Solutes & $\mathrm{mg} \mathrm{L}^{-1}$ & 270 & 345 & - & - & - & - \\
\hline Total Organic Carbon & $\mathrm{mg} \mathrm{L}^{-1}$ & 0.098 & 40.9 & 30 & 5 & 10 & 15 \\
\hline Total Nitrogen & $\mathrm{mg} \mathrm{L}^{-1}$ & 0.710 & 5.046 & 30 & 1 & 2 & 3 \\
\hline $\mathrm{NH}_{4}^{+}$ & $\mathrm{mg} \mathrm{L}^{-1}$ & 0.028 & 0.365 & 12.8 & 0.5 & 1.5 & 2 \\
\hline $\mathrm{NO}_{3}^{-}$ & $\mathrm{mg} \mathrm{L}^{-1}$ & 2.717 & 0.057 & 102 & 50 & 50 & 50 \\
\hline $\mathrm{Cl}^{-}$ & $\mathrm{mg} \mathrm{L}^{-1}$ & 13.81 & 21.22 & 1000 & 250 & 250 & 250 \\
\hline $\mathrm{PO}_{4}{ }^{3-}$ & $\mathrm{mg} \mathrm{L}^{-1}$ & 0.828 & 1.316 & $\begin{array}{c}9.2 \\
\text { (Pog) }\end{array}$ & 0.4 & 0.7 & 0.7 \\
\hline $\mathrm{SO}_{4}{ }^{3-}$ & $\mathrm{mg} \mathrm{L}^{-1}$ & $<$ LOQ & $<\mathrm{LOQ}$ & 500 & 250 & 250 & 250 \\
\hline $\mathrm{Na}^{+}$ & $\mathrm{mg} \mathrm{L}^{-1}$ & 10.70 & 13.63 & 800 & - & - & - \\
\hline $\mathbf{K}^{+}$ & $\mathrm{mg} \mathrm{L}^{-1}$ & 3.24 & 5.27 & 80 & - & - & - \\
\hline $\mathbf{M g}^{2+}$ & $\mathrm{mg} \mathrm{L}^{-1}$ & 12.49 & 12.23 & - & - & - & - \\
\hline $\mathbf{C a}^{2+}$ & $\mathrm{mg} \mathrm{L}^{-1}$ & 46.60 & 53.85 & - & - & - & - \\
\hline Dibutyl phthalate & $\mathrm{mg} \mathrm{L}^{-1}$ & $<$ LOQ & $<$ LOQ & - & - & - & - \\
\hline Bis(2-ethylhexyl) phtalate & $\mathrm{mg} \mathrm{L}^{-1}$ & $<$ LOQ & $<$ LOQ & - & - & - & - \\
\hline$\sum 16 \mathrm{PAH}$ 's & $\mathrm{mg} \mathrm{L}^{-1}$ & $<\mathrm{LOQ}$ & $<$ LOQ & - & 0.0002 & 0.0002 & 0.001 \\
\hline Cd & $\mathrm{mg} \mathrm{L}^{-1}$ & $<$ LOQ & $<\mathrm{LOQ}$ & 0.4 & 0.005 & 0.005 & 0.005 \\
\hline Zn & $\mathrm{mg} \mathrm{L}^{-1}$ & $<$ LOQ & 0.4797 & 2 & 3 & 5 & 5 \\
\hline $\mathbf{P b}$ & $\mathrm{mg} \mathrm{L}^{-1}$ & $<$ LOQ & 0.0235 & 0.5 & 0.05 & 0.05 & 0.05 \\
\hline $\mathbf{C u}$ & $\mathrm{mg} \mathrm{L}^{-1}$ & $<$ LOQ & 0 & 0.5 & 0.05 & 0.05 & 0.5 \\
\hline
\end{tabular}




\section{Table 5 (on next page)}

Physicochemical parameters of leachate water - pool 1 and 2 


\begin{tabular}{|c|c|c|c|c|c|c|c|c|c|c|c|}
\hline \multirow{3}{*}{ Parameter } & & \multicolumn{5}{|c|}{ Pool 1} & \multicolumn{5}{|c|}{ Pool 2} \\
\hline & & \multicolumn{5}{|c|}{ Period [days] } & \multicolumn{5}{|c|}{ Period [days] } \\
\hline & & 0 & 21 & 68 & 99 & 120 & $\mathbf{0}$ & 21 & 68 & 99 & 120 \\
\hline Reaction & $\mathrm{pH}$ & 8.71 & 8.51 & 8.34 & 8.27 & 8.22 & 3.87 & 4.41 & 5.23 & 6.22 & 6.25 \\
\hline Temp. & ${ }^{\circ} \mathrm{C}$ & 26.4 & 25.7 & 24.30 & 12.60 & - & 26.1 & 26.1 & 25.60 & 11.20 & - \\
\hline DO & $\mathrm{mg} \mathrm{L}^{-1}$ & 6.73 & 1.28 & 1.44 & 1.55 & 1.98 & 7.38 & 2.5 & 2.81 & 2.95 & 4.07 \\
\hline Conduct. & $\mu \mathrm{S} \mathrm{cm}^{-1}$ & 430 & 437 & 411 & 343 & 329 & 1048 & 798 & 702 & 662 & 606 \\
\hline TS & $\mathrm{mg} \mathrm{L}^{-1}$ & 25 & 10 & 5 & 13 & 3 & 20 & 20 & 2 & 32 & 2 \\
\hline Solutes & $\mathrm{mg} \mathrm{L}^{-1}$ & 29.5 & 250 & 238 & 230 & 222 & 405 & 530 & 534 & 441 & 417 \\
\hline TOC & $\mathrm{mg} \mathrm{L}^{-1}$ & 1.62 & 16.82 & 17.01 & 13.55 & 12.57 & 3.82 & 18.37 & 14.25 & 11.66 & 10.66 \\
\hline TN & $\mathrm{mg} \mathrm{L}^{-1}$ & 0.769 & 1.539 & 1.447 & 1.333 & 1.301 & 0.784 & 2.445 & 3.126 & 2.827 & 2.795 \\
\hline $\mathrm{NH}_{4}^{+}$ & $\mathrm{mg} \mathrm{L}^{-1}$ & 0.020 & 0.158 & 0.162 & 0.264 & 0.366 & 0.056 & 0.773 & 2.183 & 2.463 & 2.542 \\
\hline $\mathrm{NO}_{3}{ }^{-}$ & $\mathrm{mg} \mathrm{L}^{-1}$ & 2.394 & 0 & 0.030 & 0 & 0.100 & 2.780 & 2.472 & 0.267 & $<$ LOQ & 0.105 \\
\hline $\mathrm{Cl}^{-}$ & $\mathrm{mg} \mathrm{L}^{-1}$ & 14.76 & 18.20 & 15.97 & 14.09 & 13.72 & 191.4 & 204.4 & 201.7 & 181.1 & 177.5 \\
\hline $\mathrm{PO}_{4}{ }^{3-}$ & $\mathrm{mg} \mathrm{L}^{-1}$ & 6.047 & 0.621 & 0.338 & 0.187 & 0.082 & 0.674 & 3.312 & 0.418 & 0.057 & 0.020 \\
\hline $\mathrm{SO}_{4}{ }^{3-}$ & $\mathrm{mg} \mathrm{L}^{-1}$ & 0 & 0 & 1.443 & 1.259 & 2.293 & $<\mathrm{LOQ}$ & $<$ LOQ & 46.14 & 41.78 & 42.44 \\
\hline $\mathbf{N a}^{+}$ & $\mathrm{mg} \mathrm{L}^{-1}$ & 10.84 & 10.86 & 10.39 & 8.56 & 8.02 & 11.42 & 11.98 & 10.26 & 10.42 & 9.65 \\
\hline $\mathbf{K}^{+}$ & $\mathrm{mg} \mathrm{L}^{-1}$ & 3.19 & 3.29 & 3.33 & 2.84 & 2.74 & 3.28 & 3.39 & 3.14 & 3.21 & 3.04 \\
\hline $\mathrm{Mg}^{2+}$ & $m g L^{-1}$ & 11 & 10.67 & 10.24 & 8.63 & 8.08 & 11.22 & 12.49 & 11.36 & 11.38 & $\begin{array}{c}10.68 \\
59\end{array}$ \\
\hline $\mathrm{Ca}^{2+}$ & $\mathrm{mg} \mathrm{L}^{-1}$ & 52.67 & 51.79 & 36.74 & 32.36 & 34.14 & 54.44 & 61.80 & 56.51 & 56.80 & 53.60 \\
\hline $\begin{array}{c}\text { Dibutyl } \\
\text { phthalate }\end{array}$ & $\mathrm{mg} \mathrm{L}^{-1}$ & $<\mathrm{LOQ}$ & 0.08 & $<$ LOQ & $<\mathrm{LOQ}$ & $<$ LOQ & $<\mathrm{LOQ}$ & 0.05 & $<\mathrm{LOQ}$ & $<\mathrm{LOQ}$ & $<$ LOQ \\
\hline $\begin{array}{c}\text { Bis(2- } \\
\text { ethylhexyl } \\
\text { ) phtalate }\end{array}$ & $\mathrm{mg} \mathrm{L}^{-1}$ & $<\mathrm{LOQ}$ & $<\mathrm{LOQ}$ & $<\mathrm{LOQ}$ & $<$ LOQ & $<\mathrm{LOQ}$ & $<$ LOQ & $<\mathrm{LOQ}$ & $<$ LOQ & $<$ LOQ & $<\mathrm{LOQ}$ \\
\hline ¿16PAH's & $\mathrm{mg} \mathrm{L}^{-1}$ & $<$ LOQ & $<\mathrm{LOQ}$ & $<\mathrm{LOQ}$ & $<\mathrm{LOQ}$ & $<\mathrm{LOQ}$ & $<$ LOQ & $<\mathrm{LOQ}$ & $<\mathrm{LOQ}$ & $<\mathrm{LOQ}$ & $<\mathrm{LOQ}$ \\
\hline $\mathrm{Cd}$ & $\mathrm{mg} \mathrm{L}^{-1}$ & $<$ LOQ & 0.010 & $<$ LOQ & $<\mathrm{LOQ}$ & $<\mathrm{LOQ}$ & $<$ LOQ & 0.082 & $<$ LOQ & $<$ LOQ & $<\mathrm{LOQ}$ \\
\hline $\mathbf{Z n}$ & $\mathrm{mg} \mathrm{L}^{-1}$ & $<\mathrm{LOQ}$ & $\begin{array}{c}0.015 \\
9\end{array}$ & $<$ LOQ & $<$ LOQ & $<\mathrm{LOQ}$ & 0.110 & 0.139 & $<\mathrm{LOQ}$ & $<\mathrm{LOQ}$ & $<$ LOQ \\
\hline $\mathbf{P b}$ & $\mathrm{mg} \mathrm{L}^{-1}$ & $<\mathrm{LOQ}$ & $\begin{array}{c}0.003 \\
5\end{array}$ & $<\mathrm{LOQ}$ & $<\mathrm{LOQ}$ & $<\mathrm{LOQ}$ & 0.015 & 0.022 & $<\mathrm{LOQ}$ & $<\mathrm{LOQ}$ & $<\mathrm{LOQ}$ \\
\hline $\mathrm{Cu}$ & $\mathrm{mg} \mathrm{L}^{-1}$ & $<\mathrm{LOQ}$ & $\begin{array}{c}0.009 \\
8\end{array}$ & $<\mathrm{LOQ}$ & $<\mathrm{LOQ}$ & $<\mathrm{LOQ}$ & $<\mathrm{LOQ}$ & 0.024 & $<\mathrm{LOQ}$ & $<\mathrm{LOQ}$ & $<\mathrm{LOQ}$ \\
\hline
\end{tabular}




\section{Figure 1}

Tyre bales used in research

(A) General view of tyre bale. (B) Detail of connection wires.

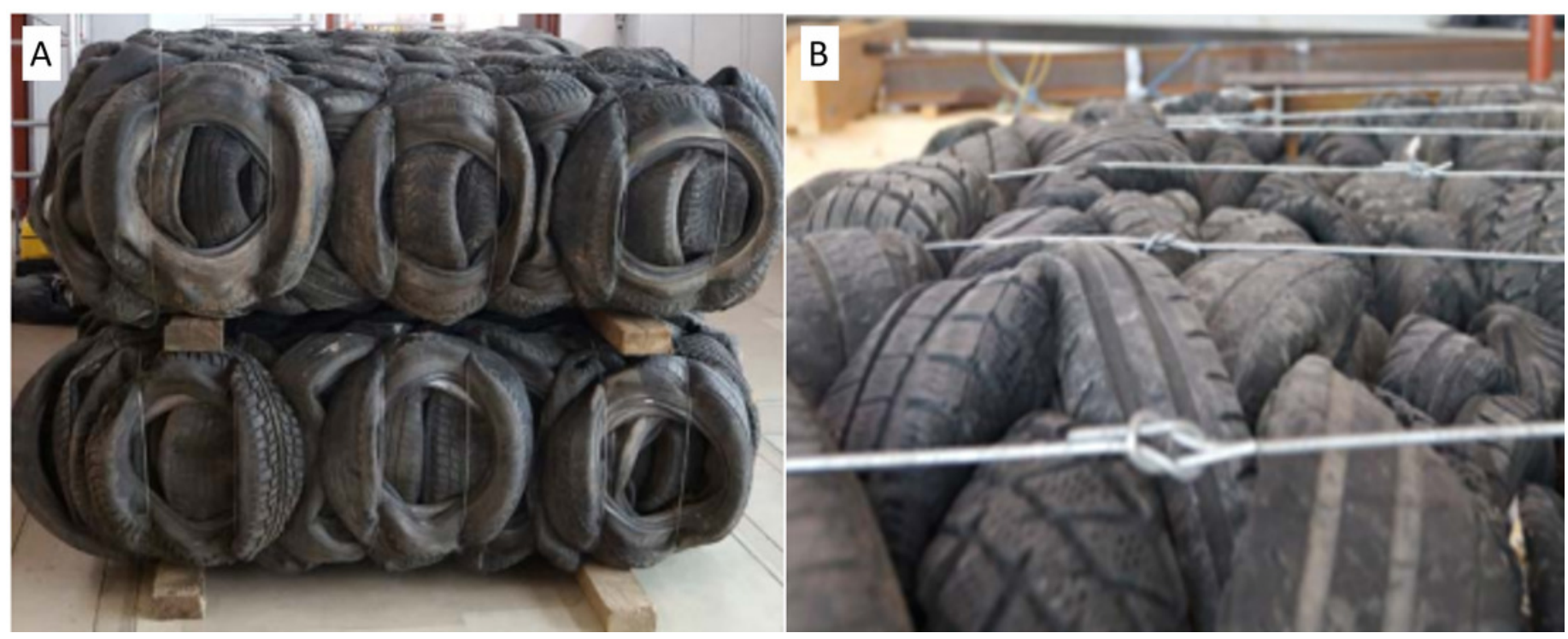


Figure 2

Stage I - washing tyres intended to perform tyre bales; testing leachate.

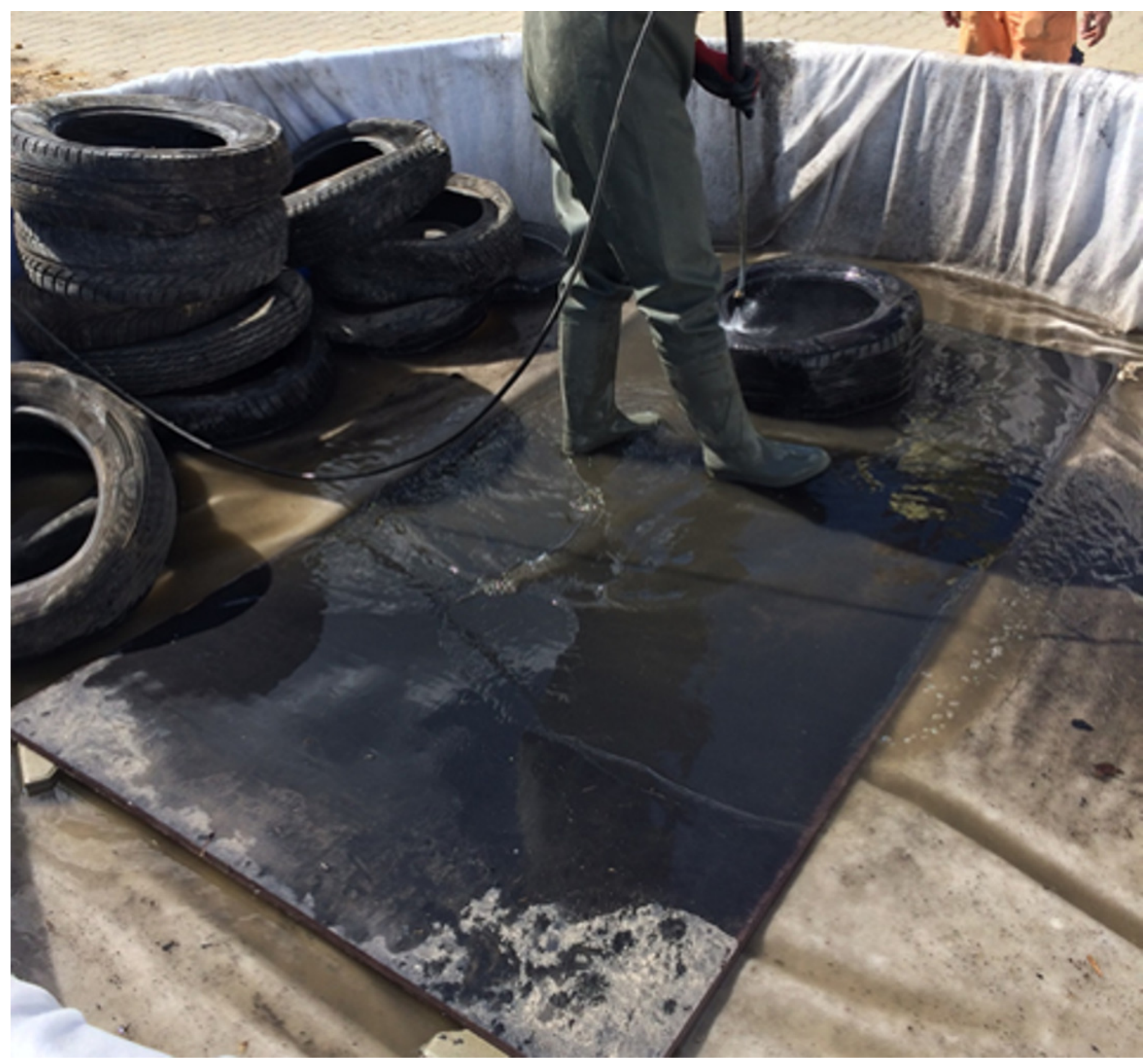


Figure 3

Leachate test trial.

(A) Tyre bale in test pool. (B) Test trial protected against atmospheric influences.

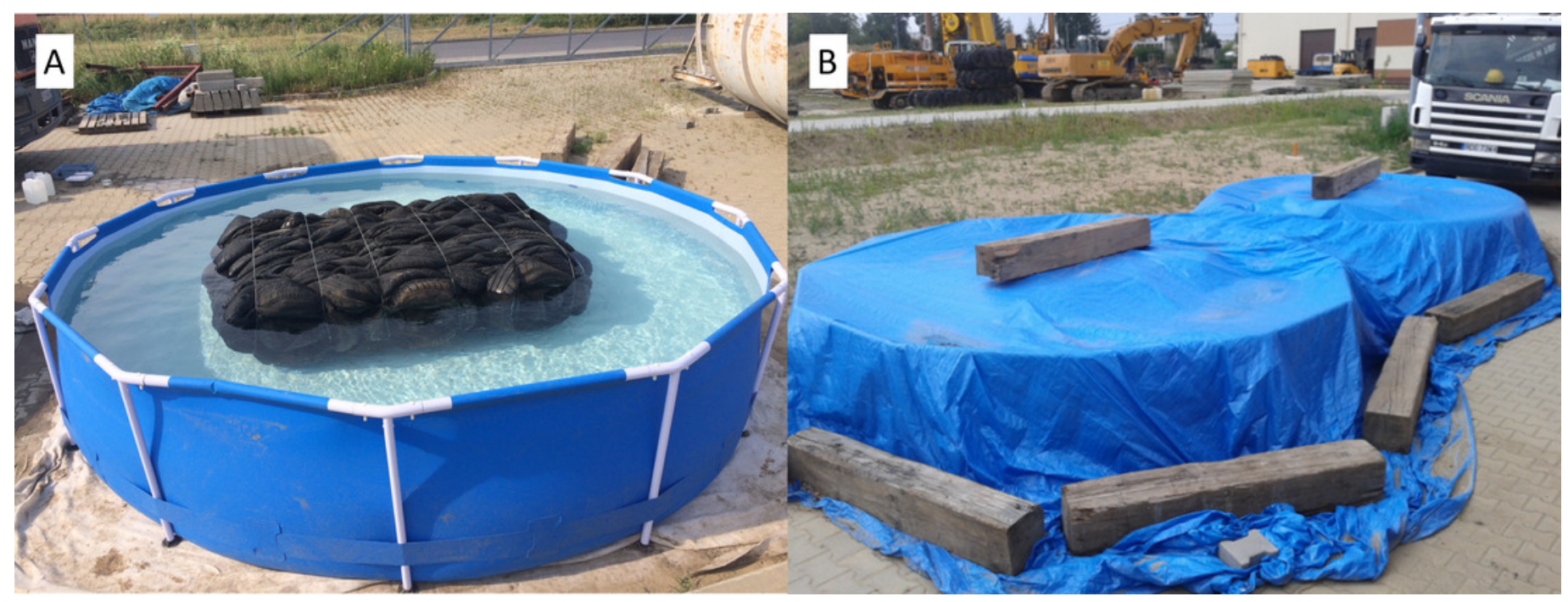




\section{Figure 4}

Full-scale trial to evaluate pressure distribution of bridge abutment backfill made of tyre bales.

Full-scale trial to evaluate pressure distribution of bridge abutment backfill made of tyre bales. (A) Installation of the moving wall between measuring chamber and backfill chamber.

(B) filling the backfill chamber with tyre bales. (C) Sampling of effluent water from the well from measuring chamber. (D) Scheme of full-scale trial.

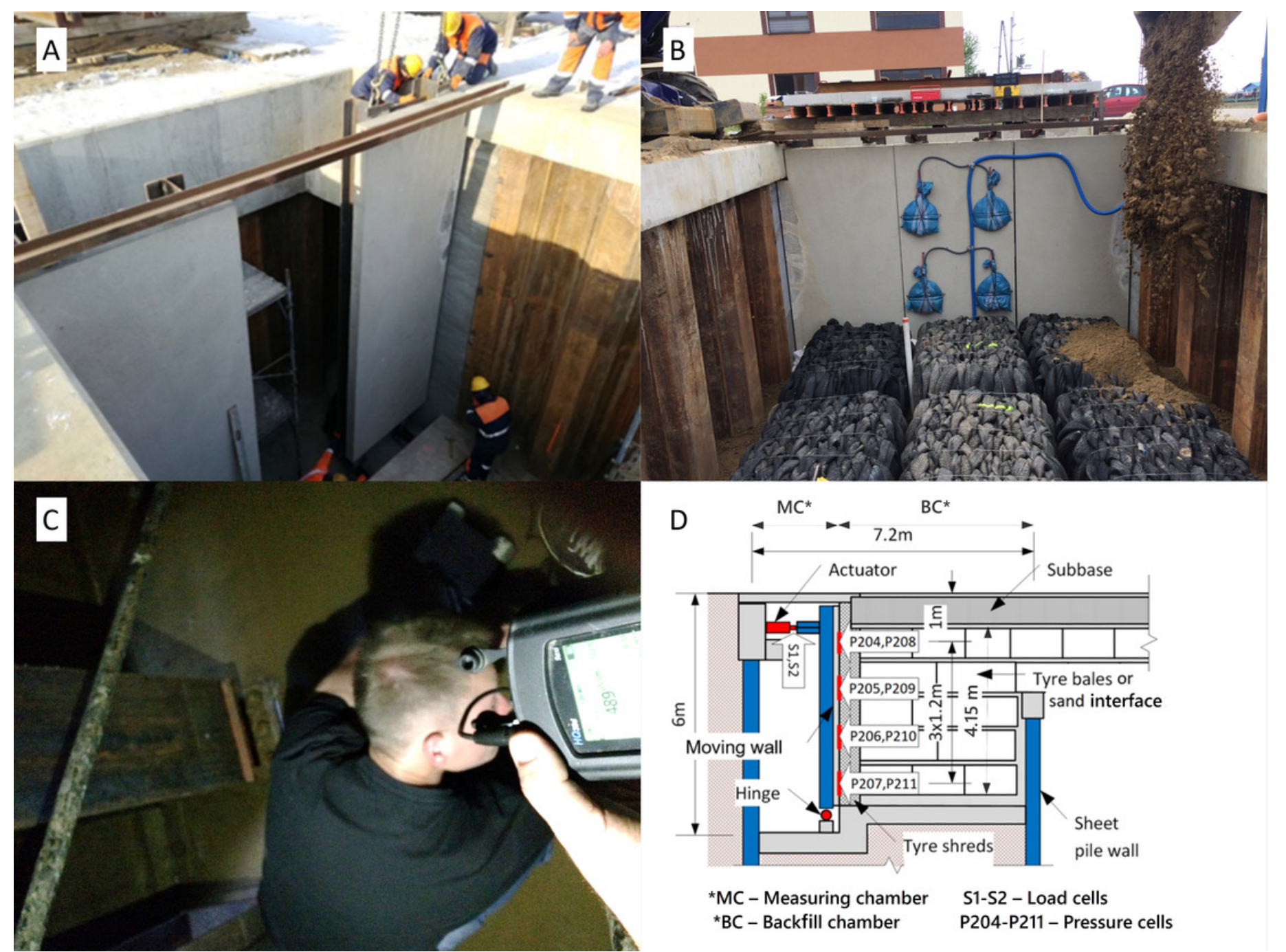

